\title{
Hughes Institute gives US science education a boost
}

\section{Washington}

WrTH $\$ 500$ million to spend on grants as a result of its settlement with the Internal Revenue Service, the Howard Hughes Medical Institute is moving into new areas of support for science education. Awards were announced last week totalling \$45 million, intended largely to complement the institute's traditional support for basic research by helping to ensure the supply of talent for biomedical research.

For non-US citizens, the new programme that will attract most attention is the provision of doctoral fellowships - 60 in 1988 and more in succeeding years until 300 are available - which are open to all graduate students, regardless of nationality. The 3-5-year fellowships are generous, with $\$ 23,000$ a year provided for living expenses and fees. Those interested will have to hurry: applications for 1988 must be in by 13 November. The job of selecting from among the applicants will be contracted to the National Academy of Sciences.

By far the largest share of the institute's new spending will go to an undergraduate biological sciences "education initiative". With $\$ 30$ million on offer, the institute will at one stroke become the biggest player in

\section{Ozone depletion over Antarctica}

THE depletion of ozone over Antarctica this year is the most severe yet (see Nature 329, 473; 1987). The stark contrast between profiles of the ozone layer at Halley Bay $\left(76^{\circ} \mathrm{S}, 27^{\circ} \mathrm{W}\right.$ ) in mid-August (left) and early October (right) is shown. The column

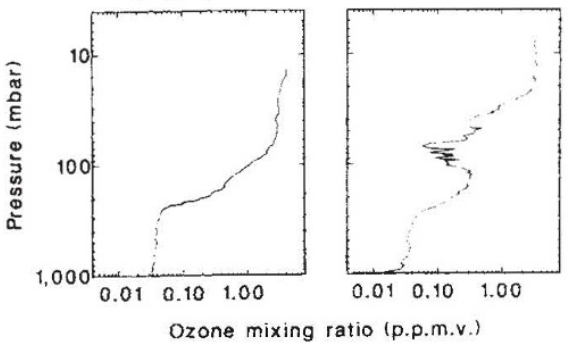

amounts on these days were 296 matm-cm and 128 matm-cm respectively (provisional values). The heart of the layer has been removed. At 70 mbar (about $16.5 \mathrm{~km}$ ), 97.5 per cent of the ozone has been destroyed. There are now two weak layers, with peak amounts at about 160 mbar (12 $\mathrm{km})$ and $22 \mathrm{mbar}(23 \mathrm{~km})$. In the core of the polar stratospheric vortex (100 to $30 \mathrm{mbar}$, 15 to $22 \mathrm{~km}$ ), ozone amount has fallen by practically an order of magnitude, from 130 to 15 matm-cm.

J.C. Farman \& B.G. Gardiner the field, surpassing spending by the National Science Foundation on improving undergraduate science education.

Ninety-four undergraduate institutions, almost 20 per cent of them with a history of high enrolments from racial minorities, have been invited to apply for individual awards in the range from $\$ 500,000$ to $\$ 2$ million. Curiously, it is the colleges that are already doing well at sending on students to biomedical research careers that have been invited to apply, rather than those that are doing badly - presumably on the grounds that the best are most able to do better.

Increasing the very low number of minority students who pursue a career in science is one explicit goal of the programme, but ideas on how biomedical education might be be improved will be sought in imaginative grant proposals rather than dictated by the institute.

Two laboratories will also receive large awards to help educational prorammes. Seven million dollars goes to the Cold Spring Harbor Laboratory for expansion of education in the neurosciences. The three-year grant will help to establish an \$11-million facility providing year-round training in advanced areas of neurobiology and provide for a permanent research programme with the emphasis on molecular approaches to neural development. Two million dollars goes to the Jackson Laboratory to improve training facilities and to increase the capacity of facilities for storing transgenic mouse embryos.

A further $\$ 5$ million will be provided at the Institute of Medicine for the development of programmes that promote public understanding of science and studies in health sciences policy. The latter are expected to help the institute to identify areas of research where development could be accelerated and where basic research discoveries could be put to use in medicine.

Alun Anderson

\section{Learned societies hit back at UK government education plans \\ London \\ from universities to host such centres in}

Proposals to create a three-tier system of scientific research and teaching in Britain's higher-education institutions have been condemned by representatives of 16 scientific societies and institutions who met in London earlier this month to discuss the document $A$ Strategy for the Science Base, produced in July by the Advisory Board for the Research Councils $(A B R C)$ at the request of the government (see Nature 328, 280; 1987).

The document's most contentious proposal is to categorize institutions into three types, with most research concentrated in about 15 'type R' institutions; a limited amount of specialized research and teaching in type $\mathrm{X}$ institutions; and teaching-only ('type T') institutions. At last week's meeting, arranged by the Biochemical Society, the proposal was rejected outright. It was concluded that "the $T$ concept is unrealistic and should be eliminated forthwith", that a combination of R- and X-type institutions would be "difficult to implement although perhaps could be acceptable". The preferred option would be for a system of type X institutions only, which should be positively developed by the ABRC and the University Grants Committee "in respect of selectivity, collaboration, concentration of scientific effort and funding, and interaction with industry".

The concept of interdisciplinary university research centres (URCs) was also decried. The Science and Engineering Research Council has already invited bids various subjects. It was concluded at the meeting that there is no evidence that the concept is viable and that in effect the URCs would be heavily funded establishments that would be difficult to dismantle were they to be ineffective or unproductive, while at the same time "starving individuals in other institutions of support for their research". The ABRC document makes "inadequate allowance for the fostering of creativity and innovation."

A further criticism of $A B R C$ is that it has neglected to consider research teaching hospitals and medical schools, particularly the question of the type of institution to which the independent medical schools in London would be attached. There is also concern about the lack of thought given to distribution of charitable funding, should the three-tier system be adopted. "Positive measures" are needed from the government to promote constructive interaction with industry, including the introduction of tax-incentive schemes.

The government says it will not make a decision on the ABRC proposals until it has considered the responses to the document, for which the deadline is $\mathbf{3 1}$ October. Nearly all of Britain's scientific societies and institutions were represented at the meeting. They will submit individual responses, and next month $\mathrm{ABRC}$ will meet with representatives of the socities and the Committee of Vice Chancellors and Principals for more discussion.

Simon Hadlington 